\section{Fortbildung? Och nö ...}

_ Zwei Fortbildungen wollte ich dieses Jahr besuchen. Ein zweitägiges Symposium zur Arbeitstherapie in Stuttgart mit Vorträgen und verschiedenen Workshops (Kosten: 80 Euro) und die Frühjahrstagung Psychiatrie in Berlin (Kosten: 40 Euro). Beide wurden abgesagt. Begründung: zu wenig Teilnehmer. Da frage ich mich, warum.

_ Das Gleiche in Grün erlebte ich vor fünf Jahren, als ich in der Psychiatrie arbeitete: Ich hatte mich für drei Fortbildungen angemeldet. Eine fand statt!

_ Es heißt doch, Ergotherapeuten sind fortbildungswillig: Die Fachtagung Neurologie war letztes Jahr ausgebucht. Den ergotag besuchen regelmäßig mehr als 300 Therapeuten. Und mindestens 1.000 Teilnehmer kommen jedes Jahr zum Ergotherapie-Kongress. Komisch, dass gerade die psychiatrischen Veranstaltungen scheitern ... Gehen diese zu wenig auf die Bedürfnisse der Ergotherapeuten ein? Oder machen die Veranstalter zu wenig Werbung?

_ Habe nur ich den Eindruck, dass sich psychiatrisch tätige Ergos weniger fortbilden? Ich erlaube mir das Vorurteil, dass die Interventionen in diesem Arbeitsfeld oft tradiert ablaufen und nicht immer betätigungsorientiert sind. Neues Wissen fließt nur langsam - zumindest scheinen das die „AbgesagtVeranstaltungen“ $z u$ bestätigen. Als gebe es die stille Angst, dass man seinen Klienten schadet, wenn man sich auf den neuesten Stand der Dinge bringt.

_ Ich freue mich darum immer sehr, wenn uns Therapeuten schreiben und ihre Konzepte oder Innovationen aus dem psychiatrischen Bereich vorstellen. Das zeigt mir, dass mein Vorurteil nichts weiter ist als ein Vorurteil. Es gibt viele Therapeuten, die neuem Wissen gegenüber aufgeschlossen sind.

_ Fehlt nur noch ein Zauber, der Fortbildungen in der Psychiatrie attraktiver macht. Vielleicht eine faszinierende Tagung mit tollen gehaltvollen Themen? Wer eine weiterempfehlen möchte, kann mir gerne schreiben.

Ich gebe übrigens nicht auf: Im Oktober habe ich mich für einen Kongress zur Ergotherapie in der Psychiatrie angemeldet. Ich freu mich schon darauf ...

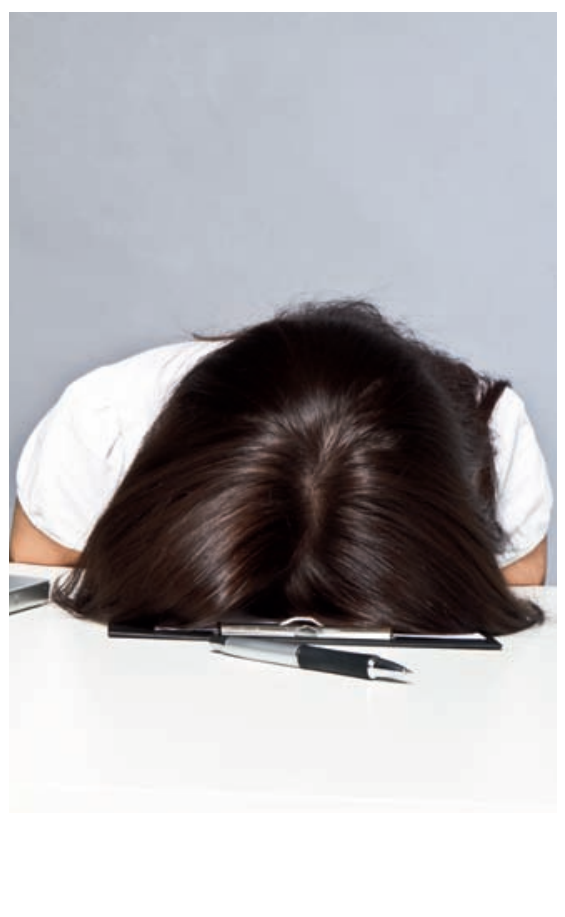

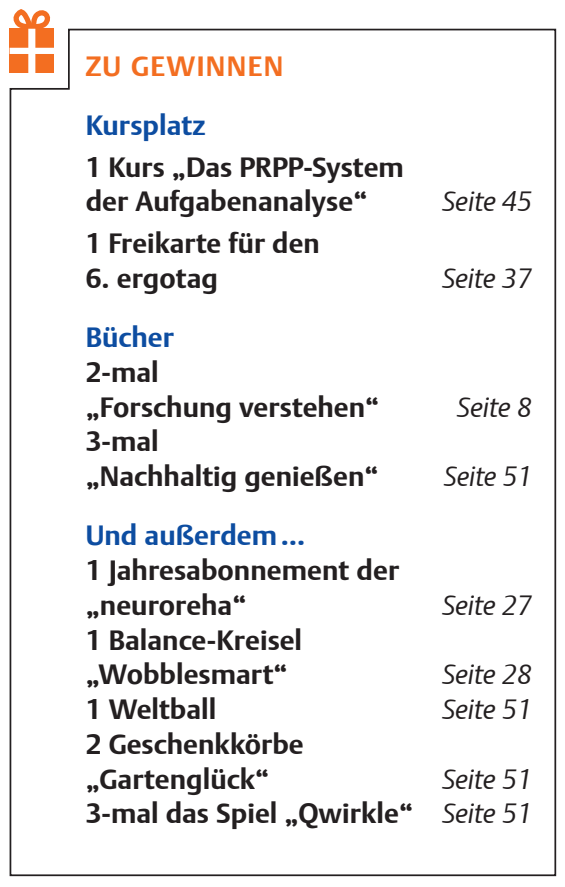

